\title{
Technology, Excretion and the Good Life
}

\author{
Tanushree Biswas ${ }^{1}$
}

\begin{abstract}
This paper discusses an ontological crisis that emerges from the modern life which is inherently related to modern technology, with insights from Heidegger's ontology of technology and my observations in Ladakh. There are two central underlying assumptions in my approach:

- "Technological" progress lies at the heart of earning the identity of being a developed country.

- The way we relate to objects of knowledge, determines the nature of knowledge.

Heidegger shows that what qualifies as science and technology for the minority world today, has not always been the way it was conceived. The validity and truth of modern knowledge is held under profound suspicion because only that which can be measured, calculated, stored, called-upon and challenged to deliver comes into being in this worldview. This tendency pervades every aspect of our lifestyles including mundane acts such as excretion. It is through such mundane acts, that relations with existence as a whole are formed and maintained and progressive knowledge is possible; knowledge which makes sustainability and the good life possible.
\end{abstract}

Key Word: Technology, Excretion, Ladakhi, Heidegger's Ontology of Technology.

\section{Introduction}

When I first proposed this text as my contribution to the conference on sustainability, I was met with a polite and hesitant feedback : could I have used a different word to discuss the subject - night-soil for example? I couldn't have used the term night-soil because of the historical and culture specific connotations it bears with it. Excretion seemed to be the most neutral term available. Ironically the question of terms already beckons us into the heart of this discussion.

Essentially, what is under consideration here is 'waste'. Jensen and McBay (2009) in their explication of the central role of the users perspective in labelling something as waste provide us with an etymological insight into words used to describe waste. The modern, polite phrase buman waste, has a negative connotation in so far as it refers to something that cannot be used. Similarly, waste, has several uses; all of them with such negative connotations. As both a noun and a verb, waste originates from the Latin vastus meaning empty and desolate, and vastare meaning to lay waste. The words devastation and devastate have the same root.

To consider some more examples discussed by Jensen and Mcbay: Skheid the root for the word shit, means to separate (from the body). Excrement, a comparatively polite term (a form of which I have politely used in the title) is traced back to the Latin excrementum from excernere which similarly means to separate or sift out. It is held to originally have 
referred to any bodily secretion until the mid-eighteenth century, when it supposedly began to be used strictly to refer to shit. Crap and its ancestor words referred to chaff or siftings from grain or other forms of residue or leftovers; only about 160 years ago did crap begin to mean shit. Dregs or sediment were initially referred to as feces. It was once considered rather polite to use the word piss, as we might currently use the term urinate. The origins of these words, as Jensen and Mcbay claim, are 'descriptive, rather than emotional, and don't reflect a particularly negative attitude toward shit.' Words for some of the places where we shit, didn't have negative connotations either. Toilet until a bit more than a century ago was a dressing room; Lavare, Latin for to wash is the root for both latrine and lavatory.

Similarly words for garbage (which meant leftover parts of slaughtered animals) have neutral and descriptive origins. For example trash has roots in Scandanavian words for fallen leaves and twigs, or rags. Litter, likewise, meant that which falls to the forest floor. Rubbish is apparently related to rubble, the word for bits of broken stone. Old, but reusable materials were called junk, while refuse can be traced back to the Latin refundere, meaning to pour or give back in the sense of restore. Which brings us back to the idea of "waste". Whether it is in the sense of physical products (to throw in a wastebasket), the process of decay (a body wasting away from cancer), destruction or obliteration (Dresden was laid to waste or he was so wasted lasted night), or places which cannot support life (wastelands), the various meanings share two concepts, namely: utility and destruction. Jensen and Mcbay further point out that fundamentally, that which is being wasted is either not being used to its full potential, or cannot be further used (a waste of time or money; a wasted life).

In so far as utility is concerned, they argue that there is a user whose perspective is central in determining whether or not something is 'waste' (ibid.) or for that matter any of the other terms discussed so far. Excretion in this context appeared to be the most neutral term and it is in a rather neutral sense that I intend to use it.

This paper discusses an ontological crisis that emerges from the modern life. The kind of life and ontological crisis to be discussed is inherently related to modern technology.

There are two central underlying assumptions in my approach:

- "Technological" progress lies at the heart of earning the identity of being a developed country.

- $\quad$ The way we relate to objects of knowledge, determines the nature of knowledge.

In order to discuss the ontological crisis, I will put forth Martin Heidegger's thesis about the essence of modern technology and its dangers. Section two shall focus upon the case of a local dry toilet system in Ladakh (India). In discussing the differences between the traditional Ladakhi and the modern methods of excretion, I will argue for the link between the ontological crisis (which Heidegger was profoundly preoccupied with) and the way a society relates to excreta. Further, I will use the example of toilet systems to suggest an epistemic loss not only in the daily lives of the Ladakhi people, but the scientific community and the world at large.

\section{Section I}

\section{Theory : Heidegger's Ontology of Technology}

In his pursuit to understand the fundamental question of Existence - Heidegger engaged with questioning the essence of technology. Understanding the essence of 
technology has similar predicaments as that of trying to understand Language. Just like the absurdity that one can't help but use language to understand Language, one uses technology to understand itself. This in the Marcelian framework (Marcel 1949) would classify as a mystery and not a problem.

A problem is one wherein I can take a distance from it, while a mystery is when I am in it, in the existential sense. With this awareness I move on to reflect with Heidegger on the question concerning technology.

Heidegger's interest in the question "what is technology" is an ontological inquiry taken on in order to enter into a right relationship with technology. It is situated within his larger research into the question What is Being?, in so far as technology reveals the Being of beings.

It follows that this question is not being asked in the ontic realm i.e. by what is technology, we do not mean what are particular apparatuses, gadgets and machines. Rather we are interested in the essence of technology or the ontological structure which is the ground for such particular occurrences. The essence of technology therefore, is not something technical.

What then, is, Technology? Two possible responses are :

1. It is a means to an end.

2. It is a human activity.

Heidegger deems both responses as correct, but not true. They have the potential to lead us to the essence of technology, but are not the essence of technology. The first response implies an instrumental understanding of technology as being functional or useful in attaining a goal. As soon as a particular object breaks down or is unable to perform its function, it reveals itself as useless to me. In other words the instrumental value of modern technology is temporary; whether it has an intrinsic value is debatable.

Using objects as an means to an end is also something that chimpanzees do; for example when a chimpanzee uses a stick to get a banana off a tree. However these cannot qualify as 'tools' because they lack the referential context of instrumentality. In sections 16, 17 and 18 of Being and Time, Heidegger presents his tools analysis to elucidate how we experience tools or equipments. In moving from the ontic to the ontological, Heidegger discovers our relationship to the world through what he calls the 'ready-to-hand' (Zubandenheit). We do not experience just matter and form when we initially encounter things in the world. At first things reveal themselves as instrumental, ready-to-hand, or 'available'. When I see something, its utility or in-order-to-ness in my project reveals itself to me as belonging to the referential context. The thing appears to be at my disposal for me to use as a means to my ends. As the structure of the 'ready-to-hand' breaks down, a mode of being that unfolds is known as 'present-at-hand' (Vorbandenheit). Founded on the Zuhandenheit mode of being, Vorhandenheit is another way we relate to the world wherein the object is present, but of no use and one can only helplessly stare at it. For example, when a cup falls and breaks, it reveals itself to me as a 'broken cup' incapable of holding liquid and not just pieces of china, rearranged.

When we first encounter a thing, it lights up a context of situatedness and a shows us a world. The whole which determines the parts (things in the world) is the world that is discovered. We discover our environment through the 'ready-to-hand' mode of being. Further, we discover that the world which is revealed is a world we are existentially in and are related to. 
The structure of 'in order to' contains a reference of something to something ... In accordance with their character of being usable material, useful things are always in terms of their belonging to other useful things: writing materials, pen, ink, paper, desk, blotter, table, lamp, furniture, windows, doors, room. (Being and Time 64)

\section{Causation:}

The understanding of instrumentality presupposes causality i.e. the means-end relation requires a cause-effect relation to function. Broadly what is classified as western thought, is an offspring of the Greek thought. Hence, the fourfold theory of causality of Aristotle is held to be the soil where the western understanding of causality is rooted.

Aristotle presents his theory of fourfold causation about physical change in Physics (Book II Section 3, numbering mine). Preliminarily he explains the senses of cause which eventually develops into four kinds of causes:

- Material cause of which a thing is made and which persists. E.g. the bronze of a statue.

- Formal cause which is the form or the archetype, i.e. the statement of essence

- Efficient cause is the primary source of change or coming to rest e.g. a man who gives the motivating advice, the sculptor.

- $\quad$ Final cause is the sense of end or that 'for the sake of which' a thing is done, e.g. environment and a good life is the cause of sustainable life choices.

We submit to the notion of instrumentality as disclosed in this prominent comprehension of fourfold causality when we accept technology as a 'means'. This general understanding of the Aristotelian cause makes Heidegger uneasy,

Certainly for centuries we have acted as though the doctrine of four causes had fallen from heaven as clear as daylight. ( Basic Writings 290)

He goes on to decipher what 'cause' as intended by the Greeks meant and how these four causes belong together in harmony. Heidegger's research reveals that amongst the Greeks cause which understood as that which brings some effect about has nothing to do with effecting.

The causa efficiens ... sets the standard for all causality. This goes so far that we no longer even count the causa finalis, telic finality, as causality. (Basic Writings 290)

The term cause is derived from the Roman causa which belongs to the family of the verb cadere which means to fall; it is that which brings about the turning of something into something else in a certain way. Cause (English), die Ursache (German) or causa (Roman) is a (mis)translation of the Greek aition which signifies 'being responsible for' and was originally applied to sentient beings and later to non-sentient beings.

The silver matter is co-responsible for the chalice, which in turn is indebted to the silver it comes from.

Moreover, the telos that preconfines the chalice within the bounds of consecration and bestowal. By bounds Heidegger does not imply a 'stopping factor' but that from which it begins to be what it will become after production; it gives a definition which completes. Aim or purpose are misinterpretations of telos.

Lastly, the silversmith 'gathers together' the three modes of indebtedness in considering them carefully and is not the only efficient cause. Considering carefully (Überlegen in 
German) is rooted in the Greek legein which is rooted in the the Greek apophainesthai meaning to bring forth into appearance.

The three modes are indebted to the silversmith for thinking about the 'that and how' of their appearancing as a sacrificial vessel. Thus, four modes of co-responsiblity are intimately involved in making something come into being.

The principal characteristic of being responsible is starting something on its way to arrival (Basic Writings 292). Heiddeger posits that being responsible for in the sense of starting something forward is occasioning or persuading movement ahead in a direction. Occassioning he deduces, is the essence of causality as conceived by the Greeks and not effecting.

The four modes of occasioning play together to carry forth from non-existent to existent or from potential to actual. Plato (Symposium 205b) explains that

Every occasion for whatever passes beyond the non-present and goes forward into presencing is poiesis, bringing forth.

Poiesis remarks Heidegger, is not just poetic or artistic bringing-forth, but it is also physis in the highest sense. When a flower in spring undergoes blossoming to a bloom which bursts forth by itself, it presences itself by means of physis. On the other hand a work of art owes itself bursting-forth to an artist.

The process of bringing-forth moves from concealment to unconcealment freely within what Heidegger calls 'revealing'. Heidegger's revealing is alètheia, which the Romans translate as veritas in the sense of truth as corresponding to facts or correct representation. But for Heidegger this is Entdecktheit which in English is closest to uncoverdness or unconcealement.

\section{Truth (unconcealement) and Technology:}

It may appear that we have wandered away from the question of technology, since the relation of truth to technology is an unusual one. Reestablishing the relation of causation and truth is a valuable contribution by Heidegger not only to ontology, but to science and metaphysics in general. Moreover, it has a significant say in the discussion of sustainability and the good life.

Heidegger demonstrates that bringing-forth moves within revealing and gathers within itself the four causes which underlie instrumentality which is a characterising aspect of technology. By examining instrumentality, we arrive at 'revealing' which is the possibility of all 'productive manufacturing'. Therefore, technology is not just a means to an end, but a mode of revealing.

Technology has etymological roots in technikon which means that which belongs to techne. Techne is a term used not only to describe the activities and skills of craftsman by the Greeks, but also for the arts of mind and the fine arts. Techne belongs to bringingforth, to poiesis

... From earliest times until Plato the word technè is linked with the word epistèmé. Both words are terms for knowing in the widest sense. (Basic Writings 294)

In Heideggerian thought, to know something means that one is comfortable with it, grasps it and as a result of which has a vision wherein truth can be revealed. Aristotle (The Nichomachean Ethics, Book VI) has meticulously discussed technè and epistèmè as revealing. According to Heidegger's reading of Aristotle, 
Technè is a mode of alêtheuein. It reveals whatever does not bring itself forth and does not yet lie here before us, whatever can look and turn out now one way or now another. Whoever builds a house or a ship. . . reveals what is to be brought forth, according to the terms of the four modes of occasioning. .... Thus what is decisive in techne does not lie at all in making and manipulating nor in the using of means, but rather in the revealing mentioned before. It is revealing, and not as manufacturing, that techne is a bringing forth. (Basic Writings 295)

Having established technology as a mode of revealing which presences in the realm of unconcealment (truth as aletheia), one could doubt whether the connection between technology and poiessis isn't far fetched. Moreover isn't it better to confine this understanding to handicraft techniques, since it does not suit modern industrial technology?

Modern technology is drastically different from earlier techniques since it is based on exact science, physics in particular. In this case it appears to be more correct to understand the meaning of technology within the purview of modern science. But modern physics depends heavily on technical apparatus and its progress on new technological innovations. Heidegger asks,

Of what essence is modern technology that it thinks of putting exact science to use? ( Basic Writings 296)

\section{Modern Technology:}

One of the primary characteristics of modern technology emerges as hoarding. Besides this it also bears the fundamental characteristic of revealing. The peculiarity of this revealing is a challenging (Herausfordern), which puts the unreasonable demand to nature that it supply energy which can be extracted and stored. Heidegger refers to modern human actions which excavate, exploit and exhaust natural resources on a gigantic scale, bestowing on earth almost only an instrumental value as a supplier of raw materials and resources. The raw materials which are extracted, instead of being put to use immediately are stored - handy and waiting to be called for use. In storing man buys himself a sense of security, that resources are ready, at hand for him whenever he needs.

As opposed to modern technology, the old windmill did not hoard or store natural energies and resources. Its sails unlocked the energy as they turned with the wind, yet not 'storing' it. On the other hand hauling out coal and ore reveals the planet as a coal mine and soil as mere mineral deposit, altering our relationship to it.

In most sustainable, traditional farming, a peasant's relation to his land is that of setting order 'in' it and not 'upon' it as he watches over his land. Modern technology on the other hand as observed in industrial farming, sets order 'upon' land.

Natural elements such as earth, water, fire and air are all victim to this challenging in so far as air is challenged to yield gas resources like nitrogen and earth set upon to yield ore. Setting upon is an expedient challenging of natural energies which on one hand unlocks and bares the energy, making them vulnerable and at the same time this expedition from its outset is carried out to achieve maximum yield at minimised costs. Coal in which dwells the sun's fire-energy, is unlocked and employed to produce steam that keeps factories functioning to produce for consumption.

In a brief description of the hydro-electric plant constructed into the river Rhine, Heidegger shows that the river now appears as though at our command. Hydraulic pressure gets the turbines to turn which works machines to dispatch electricity through a 
cable network. The Rhine is now reduced to being a power plant or a water supplier. Like nature in general, it reveals itself as available for our use, such that it can be stored. This mode of revealing Heidegger calls Bestand or standing-reserve.

Regulation and security are features of the challenging-forth and setting-upon. Natural energies are unlocked, transformed, stored and distributed, though this is not indeterminate. The relay-process is such that the course of revealing is regulated and secured. Whatever is ordered, stored and put on stand-by mode, ready on call for further orders is termed Bestand (standing-reserve).

The reference to the tools analysis in Being and Time i.e. the ready-to-hand (Zubandenheit) mode of being precedes the understanding of the standing-reserve (Bestand).

Thus beings are accessible in the surrounding world which in themselves do not need to be produced and are always already at hand. Hammer, tongs, nails in themselves refer to - they consist of steel, iron, metal, stone, wood. "Nature" is also discovered in the use of useful things, "nature" in the light of products of nature. ...

The forest is of timber. The mountain a quarry of rock, the river is water power, the wind is wind "in the sails". As the "surrounding world" is discovered, "nature" thus discovered is encountered along with it. ...But in this kind off discovery of nature, nature as what "stirs and strives," what overcomes us, entrances us as landscape, remains hidden. The botanist's plants are not flowers of the hedgerow, the river's "source" ascertained by the geographer is not the "source in the ground". (Being and Time 66)

Whenever man perceives, reflects upon, pays attention to etc. he is brought into the realm of unconcealment. Modes of revealing are allotted to him and he can only respond to what is given to him. In this sense, the revealing as standing-reserve itself is not created by man. In his own pursuit of nature as his own conceiving he is already claimed by the challenging by means of which he perceives nature as the standing-reserve. Thus modern technology (as a revealing that commands) cannot be held to be a human doing. The challenging gathers man into ordering and this gathering is termed as enframing (Das Gestell). Enframing is the essence of modern technology and is itself nothing technological.

Enframing means the gathering together of that setting-upon that sets upon man, i.e. challenges him forth, to reveal the real, in the mode of ordering, a standing reserve. (Basic Writings 302)

Objects such as chasis and rods which can be assembled comprise the technological class of things. Once they are assembled, the assemble and its parts are within the class of technological activity. These activities respond to the challenging (enframing) but never bring it about as such.

The German root stellen which means to set-upon is also the stem for Herstellen and Darstellen which mean producing and presenting. They pertain to poiesis since they let the presencing of something come forth into the realm of unconcealment. But producing which brings- forth and ordering which challenges are related in their essence (though radically different) because they are both ways of unconcealment (aletheia).

In enframing, unconcealement is in conformity with modern technology which reveals the real as a standing-reserve. This work of modern technology is not solely a human activity or a mere means, therefore an exclusively instrumental or anthropological definition is untenable in principle. 
According to Heidegger his epoch is the 'technological age' wherein man is 'in a particular way, challenged forth into revealing. That revealing concerns nature, above all, as the chief storehouse of standing energy reserve.' (Basic Writings 302)

He contends that the ordering human attitude and actions are seen first with the uprising of the 'exact science' called modern physics.

Modern science's way of representing pursues and entraps nature as a calculable coherence of forces. (Basic Writings 303)

Modern physics applies apparatus to nature, setting nature to show itself as a set of pre-determinable, calculable, coherent forces. The pursuit of modern physics is an entrapment if its 'object of study' - Nature. It is based on an understanding of causality which is neither the Greek aitia (modes of being responsible) nor causa. Instead it is number-centric or calculable model wherein only things which can be measured, exist or come into being. Obsessive measuring and measurability is a modern scientific practice. It reveals an objectified view of nature such that an isolated description of events leads to a de-contextualized perspective from the very outset. Moreover, it leads to a withdrawal of beings when they unconceal themselves to us. Heidegger holds that contrary to the view that technology is an application of scientific discoveries, enframing as the essence of modern technology precedes the historical emergence of modern science as well as industrial production. Thus, modern science is an application of enframing.

\section{Section II}

\section{Experience: Technē, The Ladakhi Toilet and the Desirable Dilemma of Becoming Modern}

Ladakh is an autonomous region under the state of Jammu and Kashmir which has a special status as part of the Republic of India; it occupies more than half of the state. Somehow Ladakh has much in common with the Tibetan culture, as well as other regions with a predominant Buddhist culture and is also known as Little Tibet.

Based on a subsistent, self-sufficient, agricultural way of life, the Ladakhi life seems to breathe values of a human-family, compassion and non-violence. Scientists and activists have observed (Norberg-Hodge 1991, Dana 2007, Goering et al 1993, Goldsmith et al 1995) that new socio-economic and lifestyle changes which have been introduced into this culture seem incompatible with the former way of life. My study revealed similar observations, although this does not amount to an agreement with the contention that there is a generic local resistance towards the project of modernity. It can be well observed that there is are local groups which support and welcome rapid- development and modernisation (Beek 200).

Predominantly a mountainous, barren, cold desert on a very high altitude, Ladakhis have limited natural resources (including water) to use. However as a civilisation Ladakhis have developed clever ways of adapting to their eco-culture and even today in remote areas lead very self- sufficient, healthy and peaceful lives in a way that allows them to remain closely connected with their environmental context. To illustrate, I will discuss the case of the Ladakhi toilet.

The Ladakhis traditionally use what one could term a dry compost toilet. Toilets made of local mud bricks, are situated outside the home and have two levels. The ground level is where the excreta collects and the top level is where the human squats in order to 
excrete. Both levels have entrances: the top door for deposit and the bottom door for collection. After excretion, one covers the excreta manually with mud using a shovel. One cleans oneself with scrap paper. Although Ladakh is a very cold region, it receives enough sunlight which causes the excreta to transform over time into manure. Ladakhis use this manure in their agricultural fields.

This model allows the human being to remain actively involved in the symbiotic cycle of environment. The land and the human that cultivates it, have the potential to feed each other. The Ladakhi toilet alters the human relation to their excreta; one is not expelling waste - rather one is producing nutrition for his land. In Heideggerian parlance, it allows the being of the excreta to reveal itself and gives the possibility to human beings to dwell in the symbiotic cycle of existence.

Modern technology reveals nature as a standing-reserve (Bestand) to be stored and ready to use whenever one wants. The Ladakhi toilet as well stores the excreta for use as manure. But this is not a standing-reserve, for it stands there to undergo its own process of transformation in accordance with its nature. The energy and nutrition that man unlocks from his own excreta, is not a result of a challenge or a demand placed on the resource to deliver. The process of transformation adapts itself to the seasonal cycle of the region.

In the modern toilet one expels disgusting, unwanted sewage as one flushes away the deposits to an unknown place, away from the eyes. The daily act of excretion in a modern water toilet, is an act that consistently divorces the being of the human from the being of the nature he/she comes from.

When the structure of the ready-to-hand (Zuhandenheit) breaks down (e.g. a broken cup), the present-at-hand (Vorhandenheit) reveals itself to me as I can only stare at it in vain; it becomes useless to me. The modern toilet does not allow this transition for what emerges out of the human body is immediately revealed as present-at-hand in other words - useless waste. Further, the mode of revealing is accompanied with the experience of disgust and being unwanted, suitable only for disposal.

Waste and disposal, I infer are creations of modern technology. The traditional Ladakhi culture seems to be a zero-waste culture. The only waste that is produced, is a consequence of industrially manufactured products (e.g. packaged food and beverages). The ontological category of the present-at-hand does not seem to emerge in such a culture as things do not become useless, their potential only alters itself.

\section{The Desirable Dilemma of Becoming Modern:}

With the pressure to globalise, implementation of colonial models of factory education and the influx of tourism the sentiment of feeling 'backward' and 'underdeveloped' seems to become stronger in the so-called Ladakhi identity (Biswas 2013). Remote areas where there are no post offices, public transport systems and limited possibilities of using the telephone, have satellite digital televisions. Information about modern lifestyles that enters these eco-cultures seems to portray modernity as flawless and developed. Children who go to residential schools away from home study text books and syllabi which do not use local knowledge-resources or acknowledge Ladakhi lifestyles as 'knowledge'. At an onto-epistemological level, I encountered Ladakhis who believe they 'don't know anything', even though they know perfectly what it means to live with cattle, to produce organic manure, to make their own butter, cheese and barley 
products, have peaceful relationships, to live a happy life without speaking the language of money and so on. None of this in their perception of modernity is valid knowledge, neither is it acknowledged by relevant authorities as science (ibid.).

One of the first conversations about culture that I had with the people of the village was about their desire to install modern toilets. They seemed aware that pipes would freeze every winter, that they will incur maintenance costs and need to divert sewage, as well as install sewage treatment methods which will hamper with the sensitivity of their environment etc. Yet, the perception of the modern toilet as a passage to the 'developed' and 'educated' world somehow seemed very strong. The modern toilet appears necessary to welcome the foreign visitor in their perception. There isn't complimentary awareness or accessible support to cope with these transitions in an organic way. The Ladakhi who has been intimately involved with the process of his environment, has no idea that the idea of degrowth for example (Nørgård 2013) is emerging in countries which rank highest on the human development index today. In this sense what my informants seemed to be receiving was 'outdated information' about development. What they dis not seem to be receiving is the acknowledgement that their lifestyles are valuable and a rich sources of knowledge, and the possibility to overcome the crisis the modern world finds itself in today.

\section{Conclusion}

It may misleadingly appear as though my position is anti-technology or romanticising certain cultures or traditions. In order to clarify the risk of this impression, I articulate that I support technology in its etymological sense of techne, as a mode of revealing existence which belongs to bringing-forth or poèsis due to its ontoepistemological value.

As one reads this text, there exist cultures in the majority world at this moment which posses expert, foundational lived-knowledge on the subject. The difference is that these cultures do not document their knowledge and code it in an enframing, logical system to qualify as science and technology for the minority world.

What qualifies as science and technology for the minority world today, as Heidegger has shown has not always been the way it has been defined. Only that which can be measured, calculated, stored called-upon and challenged to deliver comes into being. Thus, the validity and truth of this knowledge and its logic is held under profound suspicion. This underlying tendency penetrates every aspect of the modern lifestyle including mundane acts such as excreting. It is through such mundane acts relations with existence as a whole are formed and maintained. It is through mundane acts like these that the possibility of progressive knowledge is possible.

Cultural erosion in self-sufficient and sustainable societies which live the good life are not only a cultural loses for its people, but an epistemological loss for the scientific community and the modern world at large. Their subsistence therefore becomes essential to efforts towards the reconciliation between human and environmental existence in so far as we are finding ways to re-integrate into cycles of sustainability. The road to reconciliation is where hope dwells as if she were at home. On the other hand, efforts which exclude epistemologically wise technologies of living, as found in Ladakh are efforts which call for preparations for a dignified exit as we are rejected by a universe much greater than our material concerns, to say the least. 
$* * *$

\section{Appendix}

Image 1: Entrance for Deposit

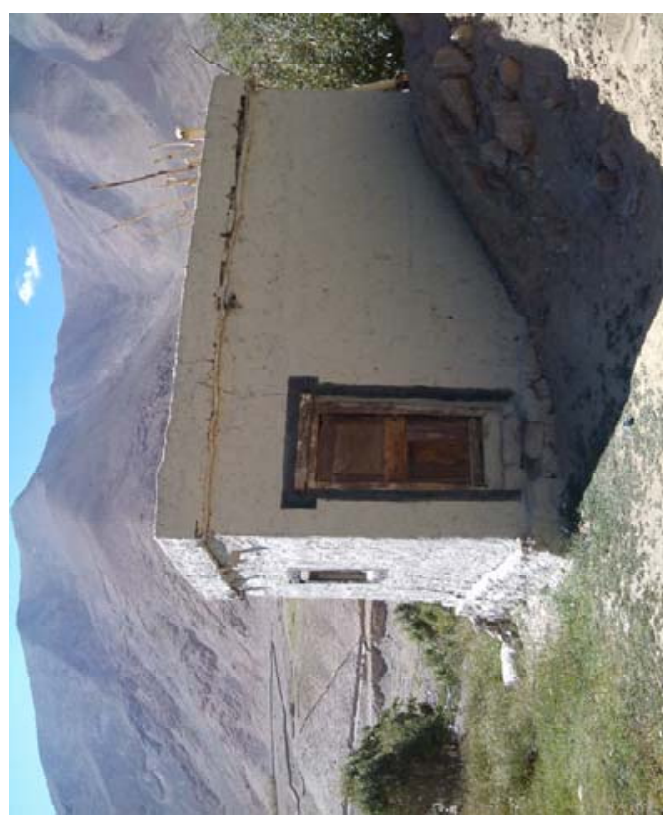

Image 3: Entrance space for Collection

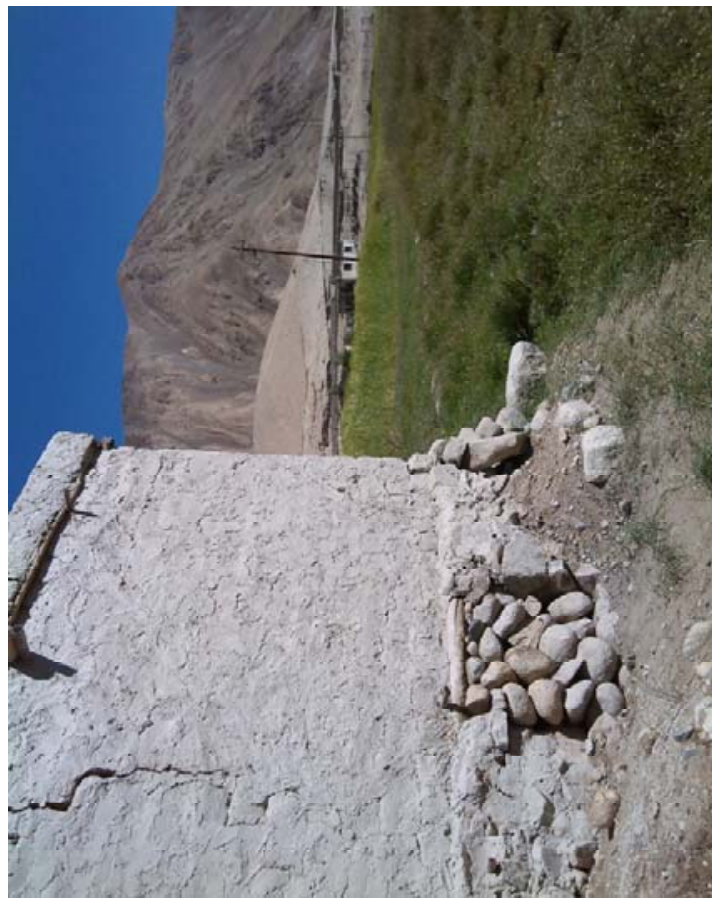

Image 2: Exterior view of the Ladakhi toilet; Window

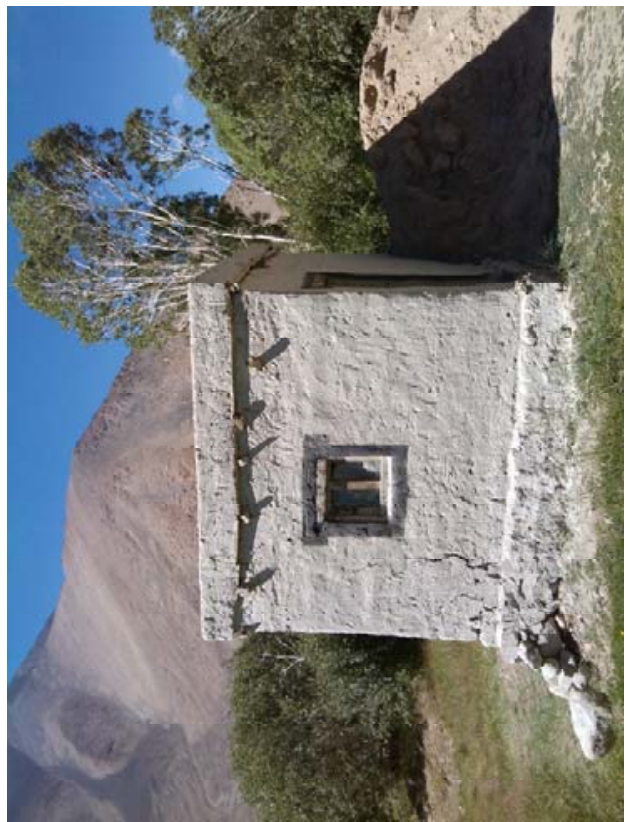

Image 4: Interior-The Deposit Space and Shovel Used to Cover Excreta with Mud

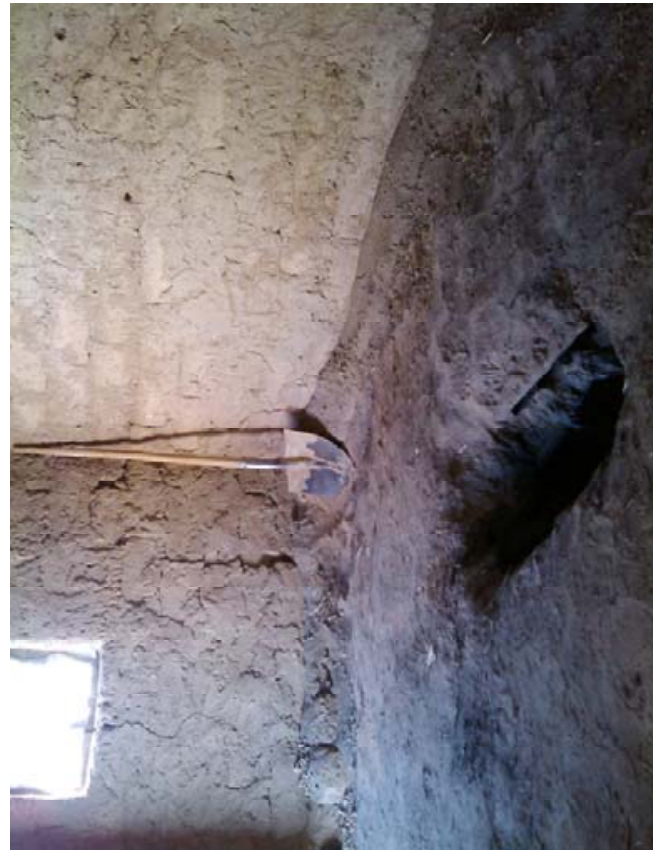


Image 5: The Depositing area and Deposits

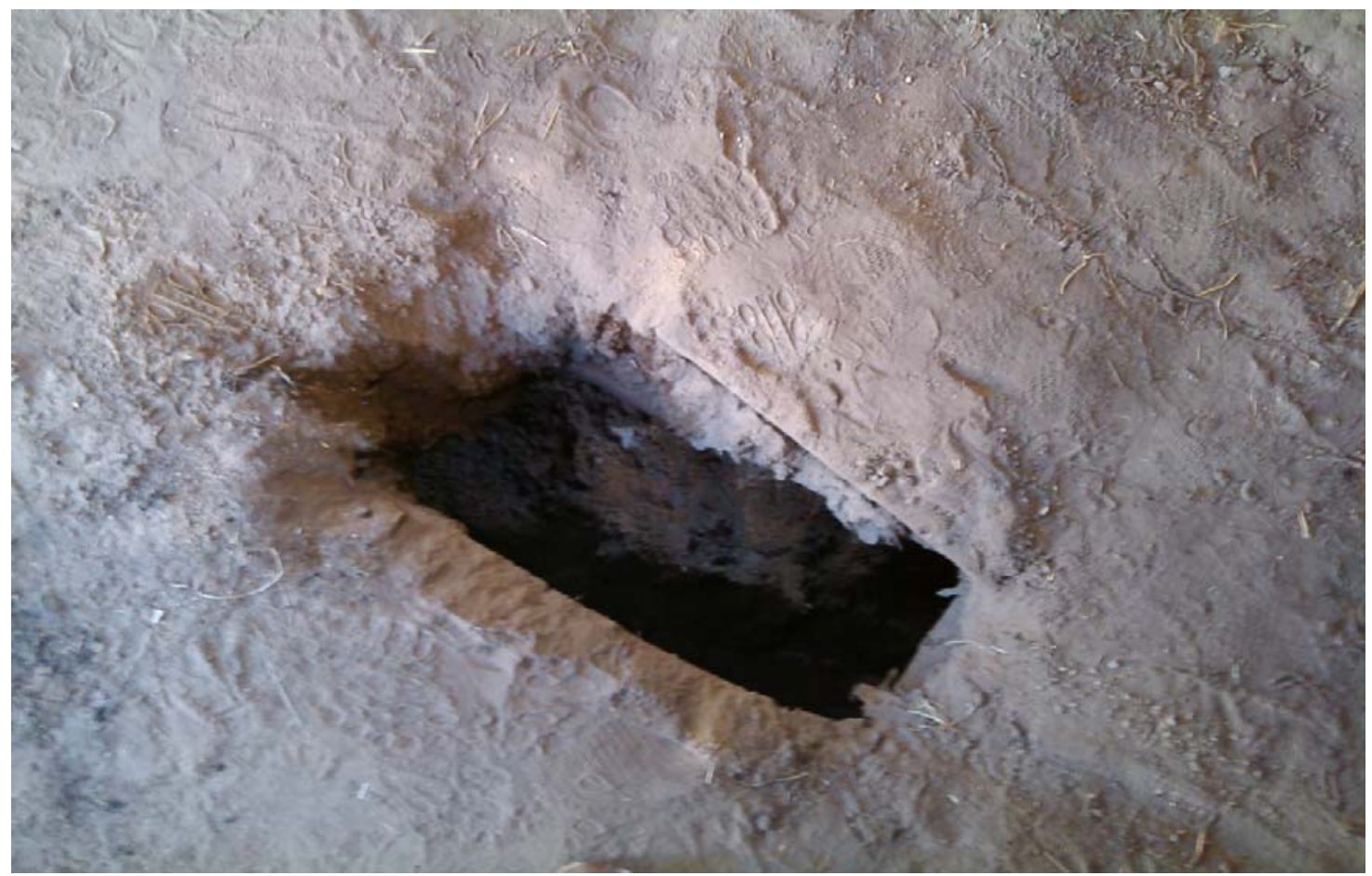

\section{References}

Aristotle (1941) The Basic Works of Aristotle (ed. McKeon, R.). Random House, New York

Biswas, T (2013) Paradoxes of Conversion: Everyday Lives of Tibetan Buddhist Child Monks in Ladakh. Norwegian

Center for Child Research, Trondheim

$<$ ntnu.diva-portal.org/smash/get/diva2:683400/FULLTEXT01.pdf> accessed 06.06.2014

Dana, J. M. R. (2007): Globalization from Below: How Ladakh is Responding to Globalization with Education. $<$ http://www.macalester.edu/educationreform/publicintellectualessay/new \%20pies/Dana\%20La dakh\%20and\%20Education\%20PIE.pdf> accessed 03.06. 2014

Goering et al (1993) From the Ground up-Rethinking Industrial Agriculture. Zed books, London

Goldsmith et al (1995) The Future of Progress- Reflections on Environment and Development. Green Books, UK

Heidegger, M (1996) Being and Time (trans. Joan Stambaugh). State University of New York Press, Albany

Heidegger, M (1977) Basic Writings (ed. Farrell, D). Harper\&Row, New York

Jensen, D and Mcbay, A (2009) What We Leave Behind. Seven Stories Press

Marcel, G (1949) Being and Having (trans. Farrer, K). Dacre Press, Westminster

Norberg-Hodge, H (1991) Ancient Futures: Learning from Ladakh. Sierra Club Books, San Fransisco

Nørgård, J.S (2013) Happy degrowth through more amateur economy. In Journal of Cleaner Production, 38: $61-70$

Plato: The Republic (trans. Benjamin, J). Project Gutenberg < www.gutenberg.org > Open Source

van Beek, M. (2000) Lessons from Ladakh? Local Responses to Globalization and Social Change.

Globalization and Social Change. (eds. Schmidt J. D. and Hersh J). Routledge, London: pp. 250-266. 